\title{
Reliability and Validity of the Experiences in Close Relationships Scale-12: Attachment Dimensions in a Clinical Sample with Eating Disorders
}

\begin{tabular}{|c|c|}
\hline Journal: & International Journal of Eating Disorders \\
\hline Manuscript ID & IJED-17-0334.R2 \\
\hline Wiley - Manuscript type: & Original Article \\
\hline Date Submitted by the Author: & 15-Nov-2017 \\
\hline Complete List of Authors: & $\begin{array}{l}\text { Tasca, Giorgio; University of Ottawa, School of Psychology } \\
\text { Brugnera, Agostino; University of Bergamo, Human \& Social Sciences } \\
\text { Baldwin, Danielle; Carleton University Department of Psychology } \\
\text { Carlucci, Samantha; University of Ottawa, School of Psychology } \\
\text { Compare, Angelo; University of Bergamo, Human \& Social Sciences } \\
\text { Balfour, Louise; Ottawa Hospital, Department of Psychology } \\
\text { Proulx, Genevieve; University of Ottawa, Department of Psychiatry } \\
\text { Gick, Mary; Carleton University Department of Psychology } \\
\text { LaFontaine, Marie-France; University of Ottawa, School of Psychology }\end{array}$ \\
\hline Keywords: & $\begin{array}{l}\text { Experience in Close Relationship Scale, Attachment, Eating Disorders, } \\
\text { Assessment, ECR-12 }\end{array}$ \\
\hline
\end{tabular}




\section{Reliability and Validity of the Experiences in Close Relationships Scale-12: Attachment Dimensions in a Clinical Sample with Eating Disorders}

Giorgio A. Tasca ${ }^{\mathrm{a}^{*}}$, Agostino Brugnera ${ }^{\mathrm{b}}$, Danielle Baldwin ${ }^{\mathrm{c}}$, Samantha Carlucci ${ }^{\mathrm{a}}$, Angelo Compare $^{\mathrm{b}}$, Louise Balfour ${ }^{\mathrm{d}}$, Genevieve Proulx ${ }^{\mathrm{e}}$, Mary Gick ${ }^{\mathrm{c}}$, Marie-France Lafontaine ${ }^{\mathrm{a}}$

${ }^{\text {a }}$ School of Psychology, University of Ottawa, Ottawa, Canada

${ }^{\mathrm{b}}$ Department of Human and Social Sciences, University of Bergamo, Bergamo, Italy

${ }^{\mathrm{c}}$ Department of Psychology, Carleton University, Ottawa, Canada

${ }^{\mathrm{d}}$ Department of Psychology, The Ottawa Hospital, Ottawa, Canada

${ }^{\mathrm{e}}$ Department of Psychiatry, University of Ottawa, Ottawa, Canada

* Corresponding author

Correspondence:

Giorgio A. Tasca, Ph.D.

University of Ottawa, 136 Jean-Jacques Lussier,

Ottawa, ON K1N 6N5, Canada

Email: gtasca@uottawa.ca

Running Title: ECR-12 and Eating Disorders 


\begin{abstract}
Objective: Attachment insecurity is a potential risk factor for the development and maintenance of eating disorders (EDs). To date, there are multiple psychometrically sound questionnaires for the evaluation of attachment in both clinical and healthy populations, such as the Experience in Close Relationship (ECR) scale. Composed by two subscales (i.e. attachment anxiety and avoidance), the ECR scale was recently adapted to a shorter, 12-item version (ECR-12). However, a validation of the ECR-12 among patients with EDs is still lacking. The present study sought to investigate the psychometric properties of the ECR-12, when used in a treatment-seeking sample with EDs. Method: A total of 1262 treatmentseeking patients with various ED diagnoses completed the ECR-12, together with a commonly used measure of ED psychopathology (Eating Disorder Inventory; EDI-2). Subsamples also completed the Attachment Style Questionnaire (ASQ; $n=66$ ) or underwent a Day Hospital Program $(n=128)$. Results: A multi-group confirmatory factor analysis indicated that the ECR-12 maintained its two-factor structure across the ED diagnostic groups. In addition, the scale demonstrated good convergent validity, internal consistency, concurrent, and incremental validity. Finally, both ECR-12 subscales demonstrated adequate test-retest reliability. Discussion: Our results provide preliminary evidence of the psychometric properties of ECR-12 in assessing attachment anxiety and avoidance among patients with EDs. This short scale could help clinicians tailor interventions for EDs that take into account attachment dimensions.
\end{abstract}

Keywords: Experience in Close Relationship Scale, ECR-12, Attachment, Eating Disorders, Assessment 


\section{Reliability and Validity of the Experiences in Close Relationships Scale-12: Attachment Dimensions in a Clinical Sample with Eating Disorders}

\section{INTRODUCTION}

Attachment theory posits that through early interactions with their caregivers infants develop an internal working model of attachment (Ainsworth, Blehar, Waters, \& Wall, 1978; Bowlby, 1969). These can be conceptualized as mental schemas, which influence one's interpersonal relationships, self-concept, and emotion regulation (Mikulincer \& Shaver, 2016a). Although originally developed as a theory of infant attachment (Ainsworth et al., 1978; Bowlby, 1969), attachment theory was later extended to adulthood and romantic relationships (Hazan \& Shaver, 1987; Shaver \& Clark, 1994).

Consistent and responsive interactions with attachment figures may lead individuals to develop greater attachment security characterized by a positive self-concept, and a view others as trustworthy and dependable (Bartholomew \& Horowitz, 1991). Inconsistent and/or unresponsive interactions with attachment figures may lead individuals to develop greater attachment insecurity, which can be conceptualized along two quantifiable dimensions: attachment anxiety and attachment avoidance (Bartholomew \& Horowitz, 1991; Brennan, Clark, \& Shaver, 1998). Individuals with high levels of attachment anxiety have difficulty trusting others, tend to hyper-activate their negative emotions and are preoccupied with fears of abandonment or rejection (Mikulincer, 1995). Individuals with high levels of attachment avoidance display a fear of intimacy, downplay the importance of relationships (Hazan \& Shaver, 1987), and tend to deactivate their emotions and limit emotional experiences (Cassidy \& Kobak, 1988). These attachment dimensions tends to be relatively stable throughout one's life (Waters, Merrick, Treboux, Crowell, \& Albersheim, 2000), though they can be altered by life events (e.g., death of a loved one, trauma, a positive romantic relationship) or therapeutic 
interventions (Bakermans-Kranenburg \& van, 2009; Pinquart, Feussner, \& Ahnert, 2013; Tasca, Ritchie, \& Balfour, 2011).

In recent years, researchers have begun to assess the implications of attachment in the development and maintenance of eating disorders (EDs; Demidenko, Tasca, Kennedy, \& Bissada, 2010; Illing, Tasca, Balfour, \& Bissada, 2010; Tasca et al., 2009). Previous research has indicated a high prevalence of attachment insecurity (i.e. anxious or avoidant) among clinical samples with EDs (Illing et al., 2010), ranging from $70 \%$ to $100 \%$ (Tasca \& Balfour, 2014). Furthermore, attachment insecurity was associated with a variety of factors implicated in ED symptomatology, including emotion dysregulation (Harrison, Sullivan, Tchanturia, \& Treasure, 2010), body dissatisfaction (Illing et al., 2010; Tasca et al., 2009), and low selfesteem (Demidenko et al., 2010). Although this model implies causation, none of the aforementioned studies directly demonstrate a causal link between early attachment and eating disorders. Research attempting to link different ED diagnoses with specific styles of attachment insecurity is limited and contradictory. For example, Tasca and Balfour (2014) suggest that types of attachment insecurity may not be related to specific ED diagnoses, but may be a transdiagnostic factor related to level of ED psychopathology. Given the mixed prognosis of EDs (Reel, 2013) and the possible implications of attachment insecurity in symptom maintenance (Tasca et al., 2009), therapeutic alliance (Folke, Daniel, Poulsen, \& Lunn, 2016), and treatment outcomes (Illing et al., 2010; Tasca, Taylor, Ritchie, \& Balfour, 2004), clinicians and patients may benefit from a brief assessment tool of attachment insecurity.

Short and psychometrically valid versions of scales could reduce the burden on clients seeking treatment (Tasca et al., 2016), and may help clinicians tailor interventions for EDs by taking into account attachment dimensions. Several self-report measures exist to assess adult attachment (Sibley \& Liu, 2004). Among them, the Experience in Close Relationships-12 
scale (ECR-12; Lafontaine et al., 2016) is a 12-item self-report measure of attachment dimensions in romantic relationships, namely Attachment Anxiety and Attachment Avoidance. The ECR-12 was derived from the original 36-item ECR (Brennan et al., 1998). Shortening a scale can reduce its content validity (Smith, McCarthy, \& Anderson, 2000), however, Lafontaine and colleagues (2016) attempted to mitigate this by using an itemresponse theory (IRT) method. Some have argued that short-form scales can be equally or more reliable than the original scale (Embretson \& Steven, 2000). The IRT method ensures that the items can discriminate well between people, and that item difficulty is adequate to assess the various levels of the constructs. It is worth noting that another short version of the ECR (ECR-S; Wei, Russell, Mallinckrodt, \& Vogel, 2007) was developed using classical test theory (CTT). As described by Lafontaine and colleagues (2016), there are a number of shortcomings when using CTT to shorten scales. For instance, item-level information is not used to select the most reliable items. Furthermore, the items extracted with CTT are only applicable to the current population, limiting its generalizability (Smith et al., 2000). For these reasons, we used the ECR-12 in this study.

An important issue in the psychometric assessment of various groups is the generalizability of tests to other populations (Messick, 1989) and external validity of results in general (Cook \& Campbell, 1979). Messick (1989) highlighted the importance of population generalizability when psychometric tests are applied to different groups. Given the possibility that each ED may have its own unique attachment profile, the present study uses the shortened ECR-12 (Lafontaine et al., 2016) to evaluate the underlying constructs (attachment anxiety and attachment avoidance), and to determine whether the ECR-12 is a valid and reliable measure of attachment when used in a clinical sample with EDs. We hypothesized that the ECR-12 will (a) demonstrate adequate construct validity, such that its two-factor structure and item-factor loadings will fit the data and be invariant across five ED diagnostic 
groups. We also hypothesized that the ERC-12 subscales will have: (b) good internal consistency reliability, (c) adequate convergent validity, such that it will be moderately positively correlated with another longer measure of attachment. Finally, we hypothesized that the ECR-12 will (d) demonstrate concurrent and incremental validity, predicting both treatment completion status and level of ED psychopathology above-and-beyond ED diagnosis. That is, even though treatment completion status and ED psychopathology may vary according to ED diagnosis (Illing et al., 2010; Tasca et al., 2004), we predict that attachment insecurity dimensions will account for additional significant variability in these outcomes.

\section{METHOD}

\subsection{Participants}

Participants in this study were 1262 adults ( $>17$ years) referred to a regional centre for the treatment of EDs in a medium-sized urban center between April 2005 and September 2015. Eating disorder diagnoses included: 119 individuals (9.4\%) diagnosed with anorexia nervosa - restrictive type (AN-R), 134 (10.6\%) with anorexia nervosa - binging purging type (ANBP), 422 (33.4\%) with bulimia nervosa (BN), 128 (10.1\%) with binge-eating disorder (BED), and 459 (36.4\%) with an eating disorder not otherwise specified (EDNOS). The majority were women (96\%) of European descent (88.4\%) with a mean age of 28.56 years $(S D=10.77)$. Most participants were single $(64 \%)$, and employed full- or part-time $(64.5 \%)$. The median family income was 60,000-69,000 Canadian dollars. The highest levels of education achieved were high-school (55.5\%) and university (43.4\%). At intake, a subset of patients $(n=128)$ were identified as requiring, and were subsequently offered, intensive treatment in the Day Hospital for EDs. They were assessed before entering the Day Hospital program and at post-treatment. These individuals' data were used for the concurrent, incremental validity, and test-retest reliability portions of this study. 


\subsection{Procedure}

The current study used archival data. Participants were initially referred to the regional centre for the treatment of EDs for a consultation by their family physicians or other medical professional. At the initial visit (i.e. consultation), participants completed a questionnaire package that included demographic information and psychological measures. Two independent doctoral level clinicians assessed the presence and type of ED using DSM-IV-TR criteria (American Psychiatric Association, 2000). The independent raters used BMI (e.g., < 17.5 for anorexia nervosa), binge-eating behaviors as defined by the Eating Disorders Examination (Fairburn \& Cooper, 1993), and presence of cognitive symptoms (e.g., drive for thinness, body image distortion, weight and shape concerns) to come to a consensus on diagnosis. Previous research demonstrated that this method of diagnosis resulted in high levels of inter-rater agreement (Tasca et al. 2009). After the initial consultation, a number of patients were admitted to the Day Hospital Program $(n=128)$, and consequently re-assessed with a psychological battery before entering the program (i.e. pre-Day Hospital). At pre DayHospital, patients completed also the ASQ $(n=66)$, a questionnaire that was added to the battery at a later time.

The Day Hospital staff included a psychiatrist, two psychologists, a nurse, a dietician, and a social worker, all of whom had at least 5 years of experience in the treatment of EDs. Patients in this program attended groups to improve mood and interpersonal functioning, for nutritional rehabilitation, and to reduce eating disordered attitudes and behaviors. Maximum length of stay in the program was 14 weeks, and minimum length for successful completion was 11 weeks. Those with AN could remain in the program longer to achieve weight stabilization at a body mass index (BMI) of $\sim 20$ during their final 2 weeks. The average length of stay in weeks for all patients was $11.21(\mathrm{SD}=4.31)$. All participants consented to be part of the study. This study was approved by the institution's Research Ethics Board. 


\subsection{Measures}

Attachment. The Experiences in Close Relationships - 12 (ECR-12; Lafontaine et al., 2016) is a 12-item self-report measure of attachment to romantic partners. Participants completed the original ECR from which the 12 items of the ECR-12 were extracted. The ECR-12 measures two dimensions of attachment to romantic partners, namely Attachment Avoidance (6 items) and Attachment Anxiety (6 items). Items are scored on a 7-point Likert scale, with higher scores indicating greater attachment avoidance and attachment anxiety with romantic partners. In the present study, Cronbach alphas of the two subscales were good (.86 in both cases).

The Attachment Style Questionnaire (ASQ; Feeney, Noller, \& Hanrahan, 1994) is a 40-item self-report measure of attachment dimensions in general (i.e. non-romantic) relationships. Items are scored on a 6-point Likert scale. The ASQ contains five subscales: Confidence in Self and Others (8 items), Need for Approval (7 items), Preoccupation with Relationships (8 items), Discomfort with Closeness (10 items), and Relationships as Secondary (7 items). Higher scores on the Preoccupation with Relationships and Need for Approval scales are associated with greater attachment anxiety, while higher scores on the Discomfort with Closeness and Relationships as Secondary scales are associated with greater attachment avoidance. Finally, higher scores on the Confidence in Self and Others scale indicate greater attachment security. In the present study, Cronbach alphas of the subscales were moderate to good (ranges .74-.94).

Eating disorder pathology. The Eating Disorder Inventory - 2 (EDI-2; Garner, 1991) is a 91-item self-report measure of the psychological characteristics and behavioural symptoms relevant for the development and maintenance of various EDs. Items are rated on 6-point Likert scale. The EDI-2 is composed of 11 subscales. Only the first three, indicative of ED psychopathology, were used in the present study, namely: Drive for Thinness (DT; 7 
items), Bulimia (B; 7 items), and Body Dissatisfaction (BD; 9 items). For this study, their items were combined into a Symptom Index $(\mathrm{DT}+\mathrm{B}+\mathrm{DB})$. In a previous study with an ED sample, the internal consistency of the three scales was good (ranges: .81 - .91; Eberenz \& Gleaves, 1994).

Treatment completion status. For the 128 patients who attended the Day Hospital Program, their treatment completion status was evaluated through a chart review using a patient evaluation form. The patient evaluation form was completed by program nurses upon discharge from the Day Hospital. Treatment completion was defined as discharge from the program after a minimum of 11 weeks or was at the discretion of the treatment team. Dropout was defined as a patient's unilateral decision for a premature termination of treatment despite therapeutic need.

\subsection{Statistical Analyses}

Construct validity was assessed with separate confirmatory factor analyses (CFA) to ensure an acceptable fit of the measurement model for each group, and for the total sample. Then we tested for invariance of the structural paths of ECR-12 model across the five diagnostic groups using a multi-group CFA. Parameters were estimated using a full maximum likelihood approach. As suggested by Byrne (2016), in multi-group CFA the structural paths are initially allowed to vary freely, and then equality constraints are imposed on the structural paths across the various groups. A small or nonsignificant difference in delta changes of fit indexes or in $\chi^{2}$ statistics between different models (i.e. unconstrained and progressively constrained models) is suggestive of an invariant structural model across the groups. Model fit was assessed using absolute, relative, and residual-based fit indexes. Optimal fit criteria were: a normed chi-squared of 3 or less, a root mean square error of approximation (RMSEA) of 0.05 or less, an upper RMSEA’s $90 \%$ confidence interval bound of 0.08 or less, a 
comparative fit index (CFI), a Gamma Hat, and a Tucker Lewis index (TLI) of 0.95 or more, and a standardized root mean squared residual (SRMR) of 0.05 or less (Hu \& Bentler, 1999).

Internal consistency reliability was investigated computing Cronbach's alpha coefficients for both ECR-12 subscales: a coefficient of at least 0.7 suggested a good internal consistency (Connelly, 2011). Test-retest was assessed through Pearson's $r$ correlation indexes and paired sample $t$-tests between ECR-12 scores obtained at two time points (initial consultation and pre-day hospital treatment). Significant correlations and non-significant $t$ tests are suggestive of an adequate stability over time (Dunn, 2012).

Convergent validity was evaluated through Pearson's $r$ correlations between ECR-12 scores and ASQ subscale scores measured at pre-Day Hospital $(n=66)$.

Concurrent and incremental validity was evaluated in three ways. First, we conducted a multivariate analysis of variance (MANOVA) followed by Tukey's post hoc comparisons, to examine whether levels of Attachment Avoidance and Attachment Anxiety differed among the five ED diagnoses (AN-R, AN-BP, BN, BED, and EDNOS). Second, we ran a hierarchical logistic regression, controlling for ED diagnosis (AN-R, AN-BP, BN, EDNOS), to assess whether ECR-12 scale scores at pre-Day Hospital predicted treatment completion (completers versus drop-outs) at post-Day Hospital. Patients with BED were not included in this analysis due to low sample size $(n=2)$. Of the 128 patients who were admitted to the Day Hospital, only 94 had complete data for all variables (i.e., completion status and ECR-12 scales). The effect of ED diagnoses was controlled in the first block of the analysis, while ECR-12 subscales in the second block. Finally, we ran a hierarchical multiple linear regression analysis to assess the association of ECR-12 Anxiety and Avoidance subscales with the EDI-2 Symptom Index. Again, we controlled for ED diagnoses in the first block (AN-R, AN-BP, BN, BED, and EDNOS), and entered the ECR-12 subscales in the second block. The latter analysis was re-run without controlling for diagnosis. 
All analyses were performed using Analysis of Moment Structures (AMOS) and Statistical Package for Social Sciences (SPSS) version 23.0. All statistical tests were twotailed, and a $p$ value $\leq .05$ was considered statistically significant.

\section{RESULTS}

\subsection{Preliminary Findings}

Preliminary analyses showed that several ECR-12 items were positively or negatively skewed: a (reverse) $\log 10$ or a square-root transformation corrected the non-normality (see figure 1 for a list of the transformed items). The resulting variables were used in CFA (Tabachnick \& Fidell, 2007). We found no univariate outliers in all variables tested. However, 24 participants were identified through Mahalanobis distance as multivariate outliers $(p<0.001)$. We ran the CFA with the 24 multivariate outliers (using the Bollen-Stine bootstrapping procedure to adjust fit statistics; Bollen \& Stine, 1992) and without the multivariate outliers, and the results were unchanged. Similarly, we ran all other analyses with and without the multivariate outliers, and the findings were almost identical. Therefore, we reported data without multivariate outliers as suggested by Tabachnick \& Fidell (2007).

ECR-12 Attachment Anxiety and most of the EDI-2 subscales at the initial consultation, as well as ECR-12 Attachment Anxiety and ASQ Preoccupation with Relationships scales at pre-Day Hospital were moderately, positively skewed. A square-root transformation corrected the non-normality. Analyses run with and without transformed variables led to similar results, therefore non-transformed variables were used and reported for ease of interpretation (Tabachnick \& Fidell, 2007). Finally, some items of the ECR-12 at the initial consultation were missing completely at random according to Little's MCAR test ( $p$ $=0.09)$. Therefore, they were imputed missing values using EM (Expectation Maximization) algorithms (Tabachnick \& Fidell, 2007).

\subsection{Main Analyses}


ECR-12 AND EATING DISORDERS

Confirmatory factor analyses. We performed a confirmatory factor analysis to assess the model fit and structural path invariance of ECR-12 across the five ED groups. Initially, we ran separate CFAs for each group and results showed a mediocre to adequate model fit to the data for each diagnostic group (see Table 1 for fit statistics and standardized factor loadings). In addition, the CFA performed on the entire sample $(\mathrm{N}=1262)$ resulted in an adequate fit: normed $\chi^{2}(53)=8.3 ;$ RMSEA $=0.076(90 \% \mathrm{CI}: 0.069,0.083) ; \mathrm{CFI}=0.95 ; \mathrm{TLI}=0.94$; Gamma Hat $=.95 ;$ RMSR $=0.63$.

With regards to the multi-group CFA, results showed that the unconstrained model (in which parameters are allowed to vary freely) had an adequate but not optimal fit of the data: two indexes (TLI and CFI) did not reach the 0.95 optimal fit criteria. Therefore, we examined Modification Indices, which suggested that treating the covariance between error terms 7 and 8, and between 1 and 2 (see Figure 1) improved the model fit. As suggested by Brown (2015), correlated errors may arise from similarly worded or reverse-worded items. The resulting unconstrained model had an optimal fit: normed $\chi 2(265)=2.19$; RMSEA $=0.031[90 \% \mathrm{CI}$ : $.027-0.034]$ CFI $=0.96 ;$ TLI $=0.95 ;$ Gamma Hat $=0.96 ;$ RMSR $=0.075$. Similarly, the model that constrained parameters to be equal across the groups fit optimally to the data: normed $\chi^{2}(365)=1.86 ;$ RMSEA $=0.026$ [90\% CI: $\left.0.023-0.029\right] ;$ CFI $=0.96 ;$ TLI $=0.96$; Gamma Hat $=0.96 ;$ RMSR $=0.093$. Differences in CFI, Gamma Hat, and $\chi^{2}$ statistics between the unconstrained and the progressively constrained models were respectively small $(<0.001)$ or non-significant, suggesting an invariant structural model across the five ED groups. Figure 1 shows the standardized factor loadings and the correlation between the two latent factors and between the error terms (1 and 2; 7 and 8) in the multi-group CFA.

Reliability. Cronbach's alpha was $\alpha=0.86$ for both Attachment Anxiety and Attachment Avoidance subscales. Results suggest that, in a sample of ED patients, both subscales have good internal consistency. 
With regards to test-retest reliability, a total of 128 participants completed the Attachment Anxiety and the Attachment Avoidance subscales a second time at pre DayHospital. The average wait-time between consultation and pre Day-Hospital was 160 days $(S D=72.00$; range $46-364)$. Both subscale scores from the initial consultation were positively and significantly correlated with the pre Day-Hospital scores (Attachment Anxiety: $r=.717, p<0.001 ;$ Attachment Avoidance $r=.754, p<0.001)$. Paired sample $t$-tests showed non-significant differences in Attachment Avoidance scores from initial consultation to preDay Hospital (Consultation $M=24.5 \pm 8.6$; Pre-DH $M=24.3 \pm 8.8$ ), $t(127)=0.488, p=$ $0.627, d=0.03$. Differences in Attachment Anxiety also were not statistically significant (Consultation $M=28.3 \pm 8.7$; Pre-DH $M=28.6 \pm 8), t(127)=-.576, p=0.57, d=-0.05$. Results suggest that the ECR-12 Attachment Anxiety and Avoidance scales are stable across time.

Convergent validity. Convergent validity was assessed examining Pearson's $r$ correlations between ECR-12 and ASQ subscales (Table 2). A total of 66 individuals who completed the ECR-12 at consultation, completed also the Attachment Style Questionnaire before entering the treatment (i.e. pre Day-Hospital). Results indicated significant, positive correlations between ECR-12 Attachment Anxiety and ASQ Need for Approval and Preoccupation with Relationships scales, both of which are conceptually related to attachment anxiety (Feeney et al., 1994). Moreover, ECR-12 Attachment Avoidance was significantly, positively associated with ASQ Discomfort with Closeness and Relationships as Secondary scales, both of which are conceptually related to attachment avoidance (Feeney et al., 1994). The Attachment Avoidance subscale was significantly, negatively associated with ASQ Confidence scale, which is a measure of secure attachment. All other correlations were not statistically significant. Results suggest that ECR-12 scales have an adequate convergent validity when assessed against the ASQ subscales of attachment. 
Concurrent and incremental validity. We performed a MANOVA to investigate the effect of eating disorder diagnoses on ECR-12 subscale scores at the initial consultation (Table 3). Results showed a statistically significant effect of diagnostic group on the linear combination of the dependent variables, Wilks Lambda $=0.967, F(8,2512)=5.383, p<.001$, $\eta^{2}=.017$, though the effect was small. Tukey's post-hoc tests for ECR-12 Attachment Anxiety scale indicated that patients diagnosed with ANR had significantly lower scores compared to those with ANBP, BN and EDNOS. No significant differences were found between ANR and BED, as well as between the other groups. Regarding ECR-12 Attachment Avoidance, Tukey`s post-hoc indicated that patients with ANR had significantly lower scores compared to ANBP, BN and EDNOS, while differences with BED were not significant. ANBP and BN had significantly higher scores compared to BED. All other comparisons were not significant. Results suggest that different EDs are associated with different patterns of attachment anxiety and avoidance.

We also performed a hierarchical logistic regression to assess the association between ECR-12 scales and completion status (completer vs drop-out) after Day Hospital treatment ( $N$ =92). The means and standard deviations on Attachment Anxiety at pre-Day Hospital were as follows: Completers $M=29.4, S D=7.85$; Drop-out $M=23.4, \mathrm{SD}=9.27$; and for Attachment Avoidance at pre Day-Hospital: Completers $M=20.4, S D=7.59$; Drop-out: $M=22.2, S D=$ 9.79. The logistic regression model containing all predictors was statistically significant, $\chi^{2}$ $(3)=11.286, p=.046$, Nagelkerke $R^{2}=18.1 \%\left(R^{2}\right.$ change $\left.=16.6 \%\right)$ of the variance in completion status, and correctly classified $80.4 \%$ of cases. Therefore, the model was able to distinguish between patients who completed the Day Hospital or dropped out. As shown in Table 4, the ECR-12 Attachment Anxiety scale was a significant predictor of completion status, with an Odds Ratio of 0.90. Thus, for every unit increase in the ECR-12 Attachment Anxiety scale, the participants were $10 \%$ less likely to drop out, controlling for the other 
factors in the model (i.e., diagnosis and ECR-12 Avoidance). Attachment Avoidance was not a significant predictor of completion status.

Finally, we ran a multiple linear hierarchical regression to evaluate the association between ECR-12 scales and the EDI-2 Symptom Index at the initial consultation. Means and standard deviations for the three EDI-2 scales and for the Symptom Index, both for the entire sample and for the five separate groups are reported in Table 3. Results demonstrated that ED diagnosis was significantly associated with ED symptoms, $F(1,1228)=75.78 ; p<.001$, and accounted for $19.5 \%$ of the variance in the EDI-2 Symptom Index. Significant comparisons between groups on EDI-2 Symptom Index values are reported in Table 3. Introducing the ECR-12 scales in the next block after ED diagnosis explained an additional $8.5 \%$ of the variance in EDI-2 Symptom Index scale, and this change in $R^{2}$ was significant, $F$ change $(2,1226)=79.53 ; p<.001$. The partial correlations for ECR-12 Attachment Anxiety and Attachment Avoidance with the EDI-2 Symptom Index were 0.28 and 0.14 , respectively $(p<$ 0.001). Therefore, both ECR-12 scales were significantly, positively associated with ED symptoms above-and-beyond ED diagnosis among treatment-seeking patients. When we reran the analysis without controlling for ED diagnoses in the first block, Attachment Anxiety and Attachment Avoidance were still positively and significantly associated with the EDI-2 Symptom Index.

\section{DISCUSSION}

The purpose of the present study was to assess the psychometric properties of the ECR-12 when used in a clinical treatment-seeking sample with EDs. The results provided support for the measure's validity and reliability across a variety of ED diagnoses.

The ECR-12 demonstrated adequate construct validity. The CFA indicated an adequate fit to the data within this large clinical sample with EDs. The results revealed high factor loadings $(>.40)$ for each of the 12 items onto their respective factors, supporting the 
two-factor structure of the ECR-12 (Lafontaine et al., 2016). Furthermore, the two scales demonstrated a small but statistically significant correlation, likely due to the large sample size. As such, the factors appear to measure distinct and somewhat independent constructs (Mikulincer \& Shaver, 2016b). A follow-up multi-group analysis indicated that the two-factor structure of the ERC-12 was maintained across the five ED diagnostic groups (i.e., ANR, ANBP, BN, BED, and EDNOS). The factor structure of the ECR-12 was invariant suggesting that the scales can be used in the assessment of multiple ED diagnoses.

The ECR-12 subscales demonstrated adequate internal consistency reliability in the present ED sample, suggesting the two scales are unidimensional (Clark \& Watson, 1995). Both the Attachment Anxiety and Avoidance subscales of the ECR-12 were stable across a relatively long period of time (i.e., 46 to 364 days), as indicated by adequate test-retest correlations and by the subscales' small and non-statistically significant differences between the two time-points. Results were in accordance with other studies that assessed the test-retest reliability of the original ECR (Alonso-Arbiol, Balluerka, \& Shaver, 2007; Panaghi, Maleki, Zabihzadeh, Poshtmashhadi, \& Soltaninezhad, 2014) and the ECR-12 (Lafontaine et al., 2016) in different populations. These findings are also consistent with research indicating the relative stability of attachment across time (Waters et al., 2000).

Correlations between the ECR-12 scales and corresponding ASQ scales provided evidence for convergent validity. The Attachment Anxiety subscale demonstrated moderate correlations with the Need for Approval and small, but statistically significant correlations with the Preoccupation with Relationships subscales of the ASQ. Moderate correlations were also found between the Avoidance subscale and the Discomfort with Closeness and the Relationships as Secondary subscales of the ASQ. These findings are consistent with the high factor loadings of the ASQ subscales onto a two-factor structure and low correlations between attachment Anxiety and Attachment Avoidance scales found in the original 
development of the ECR (Brennan et al., 1998). It also speaks to the utility of the ECR-12 scales in measuring attachment dimensions that are purported to be orthogonal.

In terms of concurrent and incremental validity, there were univariate differences between the five ED diagnostic categories on the ERC-12 subscales. Specifically, individuals with ANR had lower scores on Attachment Anxiety and Attachment Avoidance than those with ANBP, BN, and EDNOS. The differences are consistent with previous findings, whereby individuals with ANBP had higher levels of attachment anxiety (Candelori \& Ciocca, 1998) and attachment avoidance compared to individuals with ANR (Illing et al., 2010). Individuals with ANR who are severely underweight and driven to be thin may concurrently under-report or be unaware of the severity of their symptoms and attachment style, thus resulting in lower levels of self-reported attachment insecurity (Tasca et al., 2004). However, no significant differences on attachment dimensions were found between the other diagnostic groups. As indicated in previous reviews (Tasca \& Balfour, 2014), types of attachment insecurity may not be related to specific ED diagnoses, but may be a transdiagnostic factor related to level of ED psychopathology. In fact, our findings support this notion: attachment anxiety and attachment avoidance independently predicted ED symptoms above-and-beyond differences between ED diagnoses. This speaks to the potentially unique role played by attachment insecurity in maintaining ED symptoms. Recent research has evaluated potential mechanisms by which attachment insecurity may affect ED psychopathology, such as affect regulation strategies (Tasca et al., 2009).

The results also indicated that individuals with higher levels of Attachment Anxiety were more likely to complete treatment than those with lower levels. However, results indicated non-significant effects of Attachment Avoidance on treatment completion. The findings are consistent with conceptualizations that individuals with an anxious attachment tend to consistently seek support and reassurance from others (Shaver \& Mikulincer, 2002) 
and have high levels of health-seeking behaviors (Ciechanowski, Walker, Katon, \& Russo, 2002). Thus, it is possible that individuals with higher attachment anxiety are more receptive to therapeutic intervention in the form of interpersonal group support, and may be less likely to leave a therapeutic relationship even if they may not be improving or are otherwise dissatisfied. However, the results were not consistent with previous findings that attachment avoidance was related to dropping out of treatment (Tasca et al., 2006; Tasca et al., 2004). Taken together, results support the validity and potential utility of the ECR-12 and attachment dimensions in assessing and treating those with EDs.

Our study has some limitations. The sample consisted predominantly of EuropeanCanadian, educated women of a moderate socioeconomic status. Although males are being increasingly diagnosed with EDNOS (Micali, Hagberg, Petersen, \& Treasure, 2013;

Mitchison \& Mond, 2015; Raevuori, Keski-Rahkonen, \& Hoek, 2014), men (4\%) were underrepresented in this study. This may limit the generalizability of the present results to more diverse ED populations. Future studies assessing a more diverse demographic sample may provide greater insight into the mechanisms underlying attachment and EDs.

The ANR, ANBP, and BED diagnostic categories contained significantly fewer participants than the BN and EDNOS categories. This may have negatively impacted some of the cross-diagnostic comparisons and limited our ability to examine interactions in some of the analyses. In future, efforts should be made to obtain more equal sample sizes within each diagnostic group. Further limitations pertain to use of self-report measures which likely only capture consciously available information with regard to attachment. Using the Adult Attachment Interview (George, Kaplan, \& Main, 1985), for example, may be more relevant to assess less consciously available information regarding attachment states of mind. Furthermore, the participant's emotional awareness and level of distress may render some responses inaccurate. For example, individuals with higher distress may over-report 
attachment insecurity. We attempted to mitigate this factor by including diagnosis as a control variable in many analyses, however future studies may also control for level of distress in order to assess the unique effects of attachment insecurity. A final limitation was the completion of the attachment measure used to assess convergent validity. Of the 128 participants who engaged in the Day Hospital, only 66 completed the ASQ, which was a recent addition in the questionnaire package.

\section{CONCLUSION}

The present study suggests that the ECR-12, although not developed with an ED population in mind, is a reliable and valid measure of adult attachment in clinical samples with ED. The measure appears to maintain its factor structure across a variety of ED diagnoses. Eating disorders are highly complex, multifactorial psychopathologies. The assessment of attachment may highlight some factors involved in the development and maintenance of an ED, as well as assist in determining appropriate therapeutic interventions that are tailored to interpersonal and affect regulation styles specific to attachment anxiety or attachment avoidance (Tasca \& Balfour, 2014). The ECR-12 provides clinicians with a brief tool that provides a psychometrically valid assessment of attachment dimensions in patients with an ED. 
ECR-12 AND EATING DISORDERS

\section{REFERENCES}

Ainsworth, M., Blehar, M., Waters, E., \& Wall, S. (1978). Patterns of attachment. Hillsdale, NJ: Erlbaum.

Alonso-Arbiol, I., Balluerka, N., \& Shaver, P. R. (2007). A Spanish version of the Experiences in Close Relationships (ECR) adult attachment questionnaire. Personal Relationships, 14(1), 45-63. doi:10.1111/j.1475-6811.2006.00141.x

American Psychiatric Association. (2000). Diagnostic and statistical manual of mental disorders: DSM-IV-TR (4th, text revision ed.). Washington, DC: American Psychiatric Publishing.

Bakermans-Kranenburg, M. J., \& van, I. M. H. (2009). The first 10,000 Adult Attachment Interviews: distributions of adult attachment representations in clinical and nonclinical groups. Attach Hum Dev, 11(3), 223-263. doi:10.1080/14616730902814762

Bartholomew, K., \& Horowitz, L. M. (1991). Attachment styles among young adults: a test of a four-category model. (includes appendices). Journal of Personality and Social Psychology, 61(2), 226. doi:10.1037//0022-3514.61.2.226

Bollen, K. A., \& Stine, R. A. (1992). Bootstrapping goodness-of-fit measures in structural equation models. Sociological Methods \& Research, 21(2), 205-229. doi:10.1177\%2F0049124192021002004

Bowlby, J. (1969). Attachment and loss: Vol. 1. Attachment (2nd ed.). New York, NY: Basic Books.

Brennan, K. A., Clark, C. L., \& Shaver, P. R. (1998). Self-report measurement of adult attachment: An integrative overview. In J. A. Simpson \& W. S. Rholes (Eds.), Attachment theory and close relationships (pp. 46-76). New York, NY: Guilford Press. 
Brown, T. A. (2015). Confirmatory Factor Analysis for Applied Research. New York, NY: Guilford Press.

Byrne, B. M. (2016). Structural equation modeling with AMOS: Basic concepts, applications, and programming. Mahwah, NJ: Lawrence Erlbaum Associates.

Candelori, C., \& Ciocca, A. (1998). Attachment and eating disorders. In P. Bria, A. Ciocca, \& S. De Risio (Eds.), Psychotherapeutic issues on eating disorders: Models, methods, and results (pp. 139-153). Rome, IT: Società Editrice Universo.

Cassidy, J., \& Kobak, R. R. (1988). Avoidance and its relationship with other defensive processes. In J. Belsky \& T. Nezworski (Eds.), Clinical implications of attachment (pp. 300-323). Hillsdale, NJ: Erlbaum.

Ciechanowski, P. S., Walker, E. A., Katon, W. J., \& Russo, J. E. (2002). Attachment theory: a model for health care utilization and somatization. Psychosomatic Medicine, 64(4), 660-667. doi:10.1097/01.PSY.0000021948.90613.76

Clark, L. A., \& Watson, D. (1995). Constructing validity: Basic issues in objective scale development. Psychological Assessment, 7(3), 309-319. doi:10.1037/10403590.7.3.309

Connelly, L. M. (2011). Cronbach's alpha. Medsurg Nursing, 20(1), 45, 44.

Cook, T. D., \& Campbell, D. T. (1979). Quasi-experimentation: Design \& analysis issues for field settings. Boston, MA: Houghton Mifflin Company.

Demidenko, N., Tasca, G. A., Kennedy, N., \& Bissada, H. (2010). The Mediating Role of Self-Concept in the Relationship Between Attachment Insecurity and Identity Differentiation Among Women with an Eating Disorder. Journal of Social and Clinical Psychology, 29(10), 1131-1152. doi:10.1521/jscp.2010.29.10.1131

Dunn, D. S. (2012). The practical researcher: A student guide to conducting psychological research (3rd ed.). New York, NY: Wiley Global Education. 
Eberenz, K. P., \& Gleaves, D. H. (1994). An examination of the internal consistency and factor structure of the eating disorder inventory-2 in a clinical sample. International Journal of Eating Disorders, 16(4), 371-379. doi:10.1002/1098108x(199412)16:4\%3C371::aid-eat2260160406\%3E3.0.co;2-w

Embretson, S. E., \& Steven, P. (2000). Item response theory for psychologists. Mahwah, NJ: Lawrence Erlbaum Associates, Inc.

Fairburn, C. G., \& Cooper, Z. (1993). The Eating Disorder Examination (12th ed.). In C. G. Fairburn \& G. T. Wilson (Eds.), Binge eating: Nature, assessment, and treatment (pp. 317-360). New York, NY: Guilford Press.

Feeney, J. A., Noller, P., \& Hanrahan, M. (1994). Assessing adult attachment Attachment in adults: Clinical and developmental perspectives (pp. 128-152). New York, NY: Guilford Press.

Folke, S., Daniel, S. I., Poulsen, S., \& Lunn, S. (2016). Client attachment security predicts alliance in a randomized controlled trial of two psychotherapies for bulimia nervosa. Psychother Res, 26(4), 459-471. doi:10.1080/10503307.2015.1027319

Garner, D. M. (1991). Eating disorder inventory-2 (EDI-2). Odessa, FL: Psychological Assessment Resources.

George, C., Kaplan, N., \& Main, M. (1985). The Adult Attachment Interview. Department of Psychology, University of California. Berkeley, CA.

Harrison, A., Sullivan, S., Tchanturia, K., \& Treasure, J. (2010). Emotional functioning in eating disorders: attentional bias, emotion recognition and emotion regulation. Psychological Medicine, 40(11), 1887-1897. doi:10.1017/S0033291710000036

Hazan, C., \& Shaver, P. (1987). Romantic love conceptualized as an attachment process. Journal of Personality and Social Psychology, 52(3), 511-524. doi:10.1037/00223514.52.3.511 
Hu, L. t., \& Bentler, P. M. (1999). Cutoff criteria for fit indexes in covariance structure analysis: Conventional criteria versus new alternatives. Structural Equation Modeling: A Multidisciplinary Journal, 6(1), 1-55. doi:10.1080/10705519909540118

Illing, V., Tasca, G. A., Balfour, L., \& Bissada, H. (2010). Attachment insecurity predicts eating disorder symptoms and treatment outcomes in a clinical sample of women. Journal of Nervous and Mental Disease, 198(9), 653-659. doi:10.1097/NMD.0b013e3181ef34b2

Lafontaine, M.-F., Brassard, A., Lussier, Y., Valois, P., Shaver, P. R., \& Johnson, S. M. (2016). Selecting the Best Items for a Short-Form of the Experiences in Close Relationships Questionnaire. European Journal of Psychological Assessment, 32(2), 140-154. doi:10.1027/1015-5759/a000243

Messick, S. (1989). Validity. In R. L. Linn (Ed.), Educational Measurement (3rd ed., pp. 13103). New York, NY: Macmillan.

Micali, N., Hagberg, K. W., Petersen, I., \& Treasure, J. L. (2013). The incidence of eating disorders in the UK in 2000-2009: findings from the General Practice Research Database. BMJ Open, 3(5). doi:10.1136/bmjopen-2013-002646

Mikulincer, M. (1995). Attachment style and the mental representation of the self. Journal of Personality and Social Psychology, 69(6), 1203-1215. doi:10.1037/00223514.69.6.1203

Mikulincer, M., \& Shaver, P. R. (2016a). Attachment in Adulthood: Structure, Dynamics, and Change (2nd ed.). New York, NY: Guilford Press.

Mikulincer, M., \& Shaver, P. R. (2016b). Measurement of Attachment-Related Constructs in Adulthood Attachment in Adulthood: Structure, Dynamics, and Change (2nd ed., pp. 81-115). New York, NY: Guilford Press. 
Mitchison, D., \& Mond, J. (2015). Epidemiology of eating disorders, eating disordered behaviour, and body image disturbance in males: a narrative review. Journal of Eating Disorders, 3(1), 20. doi:10.1186/s40337-015-0058-y

Panaghi, L., Maleki, G., Zabihzadeh, A., Poshtmashhadi, M., \& Soltaninezhad, Z. (2014). Validity, reliability, and factor analysis of experiences in close relationship (ECR) scale. Iranian Journal of Psychiatry and Clinical Psychology, 19(4), 305-313.

Pinquart, M., Feussner, C., \& Ahnert, L. (2013). Meta-analytic evidence for stability in attachments from infancy to early adulthood. Attachment \& Human Development, 15(2), 189-218. doi:10.1080/14616734.2013.746257

Raevuori, A., Keski-Rahkonen, A., \& Hoek, H. W. (2014). A review of eating disorders in males. Current Opinion in Psychiatry, 27(6), 426-430.

doi:10.1097/YCO.0000000000000113

Reel, J. J. (2013). Eating Disorders: An Encyclopedia of Causes, Treatment, and Prevention. Westport, CT: Greenwood.

Shaver, P. R., \& Clark, C. L. (1994). The psychodynamics of adult romantic attachment. In J. M. Masling \& R. F. Bornstein (Eds.), Empirical perspectives on object relations theory (pp. 105-156). Washington, DC: American Psychological Association.

Shaver, P. R., \& Mikulincer, M. (2002). Attachment-related psychodynamics. Attachment \& Human Development, 4(2), 133-161. doi:10.1080/14616730210154171

Sibley, C. G., \& Liu, J. H. (2004). Short-term temporal stability and factor structure of the revised experiences in close relationships (ECR-R) measure of adult attachment. Personality and Individual Differences, 36(4), 969-975. doi:10.1016/s01918869(03)00165-x 
Smith, G. T., McCarthy, D. M., \& Anderson, K. G. (2000). On the sins of short-form development. Psychological Assessment, 12(1), 102-111. doi:10.1037//10403590.12.1.102

Tabachnick, B. G., \& Fidell, L. S. (2007). Using multivariate statistics (5th ed.). Boston, MA: Pearson Education, Inc.

Tasca, G. A., \& Balfour, L. (2014). Attachment and eating disorders: a review of current research. International Journal of Eating Disorders, 47(7), 710-717. doi:10.1002/eat.22302

Tasca, G. A., Cabrera, C., Kristjansson, E., MacNair-Semands, R., Joyce, A. S., \& Ogrodniczuk, J. S. (2016). The therapeutic factor inventory-8: Using item response theory to create a brief scale for continuous process monitoring for group psychotherapy. Psychotherapy Research, 26(2), 131-145. doi:10.1080/10503307.2014.963729

Tasca, G. A., Ritchie, K., \& Balfour, L. (2011). Implications of attachment theory and research for the assessment and treatment of eating disorders. Psychotherapy (Chic), 48(3), 249-259. doi:10.1037/a0022423

Tasca, G. A., Ritchie, K., Conrad, G., Balfour, L., Gayton, J., Lybanon, V., \& Bissada, H. (2006). Attachment scales predict outcome in a randomized controlled trial of two group therapies for binge eating disorder: An aptitude by treatment interaction. Psychotherapy Research, 16(1), 106-121. doi:10.1080/10503300500090928

Tasca, G. A., Szadkowski, L., Illing, V., Trinneer, A., Grenon, R., Demidenko, N., . . . Bissada, H. (2009). Adult attachment, depression, and eating disorder symptoms: The mediating role of affect regulation strategies. Personality and Individual Differences, 47(6), 662-667. doi:10.1016/j.paid.2009.06.006 
Tasca, G. A., Taylor, D., Ritchie, K., \& Balfour, L. (2004). Attachment predicts treatment completion in an eating disorders partial hospital program among women with anorexia nervosa. Journal of Personality Assessment, 83(3), 201. doi:10.1207/s15327752jpa8303_04

Waters, E., Merrick, S., Treboux, D., Crowell, J., \& Albersheim, L. (2000). Attachment security in infancy and early adulthood: a twenty-year longitudinal study. Child Development, 71(3), 684-689. doi:10.1111/1467-8624.00176

Wei, M., Russell, D. W., Mallinckrodt, B., \& Vogel, D. L. (2007). The Experiences in Close Relationship Scale (ECR)-short form: reliability, validity, and factor structure. Journal of Personality Assessment, 88(2), 187-204. doi:10.1080/00223890701268041 


\section{TABLES}

Table 1. Standardized regression weights, between-factors correlations and fit indexes for the Confirmatory Factorial Analysis in the 5 ED groups.

Table 2. Zero-order correlations between ECR-12 at Consultation and ASQ at Pre DayHospital.

Table 3. Means, SD, and Results of the MANOVA and Regression Analyses for ECR-12 Anxiety and Avoidance Across ED Diagnostic Groups.

Table 4. Hierarchical Logistic Regression of ED Diagnoses and ECR subscales predicting treatment completion status. 
Table 1.

\section{Standardized Factor Loadings}

\begin{tabular}{|c|c|c|c|c|c|}
\hline \multirow[b]{2}{*}{ Attachment Anxiety factor } & \multicolumn{5}{|c|}{ Eating Disorder Diagnostic Groups } \\
\hline & $\begin{array}{c}\text { AN-R } \\
(N=119)\end{array}$ & $\begin{array}{c}\text { AN-BP } \\
(N=134)\end{array}$ & $\begin{array}{c}\text { BN } \\
(N=422)\end{array}$ & $\begin{array}{c}\text { BED } \\
(N=128)\end{array}$ & $\begin{array}{c}\text { EDNOS } \\
(N=459)\end{array}$ \\
\hline 2. I worry about being abandoned & .79 & .83 & .81 & .80 & .81 \\
\hline 6. I worry that romantic partners won't care about me as much as I care about them & .74 & .68 & .76 & .83 & .71 \\
\hline 8. I worry a fair amount about losing my partner & .81 & .77 & .82 & .75 & .82 \\
\hline 14. I worry about being alone & .77 & .69 & .71 & .75 & .75 \\
\hline 18. I need a lot of reassurance that I am loved by my partner & .72 & .75 & 69 & .64 & .69 \\
\hline 24. If I can't get my partner to show interest in me, I get upset or angry & .49 & .51 & .51 & .53 & .49 \\
\hline \multicolumn{6}{|l|}{ Attachment Avoidance factor } \\
\hline 27. I usually discuss my problems and concerns with my partner & .93 & .89 & .86 & .92 & .90 \\
\hline 25. I tell my partner just about everything & 91 & .90 & .86 & .87 & .90 \\
\hline 31. I don't mind asking romantic partners for comfort, advice, or help & .78 & .77 & .76 & .64 & .81 \\
\hline 9. I don't feel comfortable opening up to romantic partners & .66 & .57 & .66 & .61 & .60 \\
\hline 15. I feel comfortable sharing my private thoughts and feelings with my partner & .50 & .68 & .69 & .51 & .60 \\
\hline 29. I feel comfortable depending on romantic partners & .46 & .49 & .55 & .52 & .59 \\
\hline Correlations between factors & $.25 *$ & .08 & $.22 * *$ & $.30 * *$ & .01 \\
\hline \multicolumn{6}{|l|}{ Fit Indexes } \\
\hline Normed Chi Squared $(d f=53)$ & 1.976 & 1.675 & 4.238 & 2.039 & 3.846 \\
\hline RMSEA & .09 & .07 & .09 & .09 & .08 \\
\hline RMSEA 90\% CI & $.07-.12$ & $.04-.10$ & $.08-.10$ & $.07-.12$ & $.07-.09$ \\
\hline CFI & .93 & .94 & .93 & .92 & .95 \\
\hline TLI & .91 & .95 & .91 & .90 & .93 \\
\hline Gamma Hat & .93 & .96 & .94 & .93 & .95 \\
\hline
\end{tabular}


Notes: AN-R = Anorexia Nervosa - Restrictive type; AN-BP = Anorexia Nervosa - Binging/Purging Type; BN= Bulimia Nervosa; BED = Binge Eating Disorder; EDNOS = Eating Disorder Not Otherwise Specified. ECR $=$ Experiences in Close Relationships Scale. RMSEA $=$ Root Mean Square Error of Approximation; RMSEA 90\% CI = RMSEA 90\% Confidence Intervals; CFI = Comparative Fit Index; TLI = Tucker Lewis Index; SRMR = Standardized Root Mean Squared Residual. All loadings are significant at $p<.001$. The number preceding the item (e.g., 2) represents the original item number from the 36 -item version of the ECR. * $p \leq 0.05$ (2-tailed) $* * p \leq 0.01$ (2-tailed) 
Table 2

\begin{tabular}{lccccc}
\hline \multicolumn{1}{c}{ ECR-12 Scales } & ASQ C & ASQ DC & ASQ NA & ASQ PR & ASQ RS \\
\hline Attachment Anxiety & -.119 & -.020 & $.311^{*}$ & $.488^{* *}$ & .034 \\
Attachment Avoidance & $-.278^{*}$ & $.423^{* *}$ & -.003 & -.070 & $.249^{*}$ \\
\hline
\end{tabular}

Notes: $\mathrm{N}=66$. ASQ $\mathrm{C}=$ Confidence; $\mathrm{DC}=$ Discomfort with Closeness; $\mathrm{NA}=$ Need for Approval; PR = Preoccupation with Relationships; RS = Relationships as Secondary; ECR $=$ Experiences in Close Relationships.

* $p \leq 0.05$ (2-tailed)

$* * p \leq 0.01$ (2-tailed) 
Table 3

\begin{tabular}{|c|c|c|c|c|c|c|c|c|c|c|c|}
\hline ECR-12 Scales & $\begin{array}{c}\text { Total } \\
(\mathbf{N}=\mathbf{1 2 6 2})\end{array}$ & $\begin{array}{c}\text { AN-R } \\
(\mathrm{N}=119)\end{array}$ & & $\begin{array}{c}\text { AN-BP } \\
(\mathbf{N}=134)\end{array}$ & & $\begin{array}{c}\text { BN } \\
(\mathrm{N}=422)\end{array}$ & & $\begin{array}{c}\text { BED } \\
(\mathbf{N}=128)\end{array}$ & & $\begin{array}{c}\text { EDNOS } \\
(\mathbf{N}=\mathbf{4 5 9})\end{array}$ & \\
\hline Attachment Anxiety & $28.26(9.04)$ & $25.31(9.50)$ & $\mathrm{b}, \mathrm{c}, \mathrm{e}$ & $29.03(8.54)$ & a & $28.49(9.08)$ & a & $27.53(9.29)$ & & $28.79(8.82)$ & $\mathrm{a}$ \\
\hline Attachment Avoidance & $22.58(8.69)$ & $19.90(8.36)$ & $\mathrm{b}, \mathrm{c}, \mathrm{e}$ & $25.05(8.32)$ & a, c, d & $23.10(8.77)$ & a, d & $20.63(8.23)$ & $\mathrm{b}, \mathrm{c}$ & $22.62(8.69)$ & $\mathrm{a}, \mathrm{b}$ \\
\hline EDI-2 Scales & $\begin{array}{c}\text { Total } \\
(\mathbf{N}=\mathbf{1 2 3 7})\end{array}$ & $\begin{array}{c}\text { AN-R } \\
(\mathrm{N}=\mathbf{1 1 8})\end{array}$ & & $\begin{array}{c}\text { AN-BP } \\
(\mathbf{N}=\mathbf{1 3 2})\end{array}$ & & $\begin{array}{c}\text { BN } \\
(\mathrm{N}=\mathbf{4 1 5})\end{array}$ & & $\begin{array}{c}\text { BED } \\
(\mathrm{N}=124)\end{array}$ & & $\begin{array}{c}\text { EDNOS } \\
(\mathbf{N}=\mathbf{4 5 0})\end{array}$ & \\
\hline EDI-2 DT & $14.46(5.74)$ & $10.29(6.85)$ & & $15.02(5.90)$ & & $15.70(4.66)$ & & $12.48(5.29)$ & & $14.78(5.80)$ & \\
\hline EDI-2 B & $7.62(6.07)$ & $0.94(1.94)$ & & $7.27(5.88)$ & & $11.64(5.19)$ & & $11.05(4.77)$ & & $4.84(4.67)$ & \\
\hline EDI-2 BD & $18.08(7.91)$ & $11.34(7.12)$ & & $16.48(8.45)$ & & $18.95(7.54)$ & & $21.41(6.14)$ & & $18.60(7.67)$ & \\
\hline EDI-2 SI & $40.21(15.19)$ & $22.62(13.34)$ & $\mathrm{b}, \mathrm{c}, \mathrm{d}, \mathrm{e}$ & $38.83(15.09)$ & a, c, d & $46.29(13.77)$ & $\mathrm{a}, \mathrm{b}, \mathrm{e}$ & $44.94(11.46)$ & $a, b, e$ & $38.25(13.68)$ & a, c, d \\
\hline
\end{tabular}

Notes: ECR-12 = Experience in Close Relationships Scale -12; AN-R = Anorexia Nervosa - Restrictive type; AN-BP = Anorexia Nervosa - Binging/Purging Type; $\mathrm{BN}=$ Bulimia Nervosa; BED = Binge Eating Disorder; EDNOS = Eating Disorder Not Otherwise Specified. EDI $-2=$ Eating Disorder Inventory $-2(\mathrm{DT}=$ Drive for 
Thinness; B = Bulimia; BD = Body Dissatisfaction; SI = Symptom Index). For EDI-2, $N$ refers to EDI-2 Symptom Index; EDI-2 SI was the dependent variable in regression analysis.

Superscripts refer significant differences from the reference group in multiple comparisons. Reference groups: ${ }^{\mathrm{a}}=\mathrm{AN}-\mathrm{R} ;{ }^{\mathrm{b}}=\mathrm{AN}-\mathrm{BP} ;{ }^{\mathrm{c}}=\mathrm{BN} ;{ }^{\mathrm{d}}=\mathrm{BED} ;{ }^{\mathrm{e}}=\mathrm{EDNOS}$.

(e.g., superscripts ${ }^{\text {b,c,de }}$ for the AN-R mean indicate a significant difference from AN-BP, BN, BED, and EDNOS). 
Table 4

\begin{tabular}{llcccccc}
\hline & & $\boldsymbol{B}$ & SE & Wald & $\boldsymbol{p}$ & OR & OR 95\% CI \\
\hline Step 0 & AN-R & -1.22 & 1.20 & 1.03 & 0.31 & 0.30 & $0.03-3.10$ \\
& AN-BP & -0.25 & 0.95 & 0.07 & 0.79 & 0.78 & $0.12-4.99$ \\
& BN & 0.03 & 0.62 & 0.002 & 0.97 & 1.03 & $0.31-3.43$ \\
& EDNOS & -0.03 & 0.62 & 0.002 & 0.97 & 0.98 & $0.29-3.26$ \\
Step 1 & Attachment Anxiety & -0.10 & 0.03 & 8.69 & $<0.01$ & 0.90 & $0.85-0.97$ \\
& Attachment Avoidance & 0.01 & 0.04 & 0.03 & 0.86 & 1.01 & $0.94-1.08$ \\
\hline
\end{tabular}

Notes: $\mathrm{N}=92$ due to missing values. $B=$ slope coefficient; $S E=$ standard error; Wald = Wald statistic; $p=$ significance level; $O R=$ odds ratio; $O R$ 95\% CI = odds ratio's 95\% confidence interval. AN-R = Anorexia Nervosa - Restrictive type; AN-BP = Anorexia Nervosa - Binging/Purging Type; BN= Bulimia Nervosa; EDNOS $=$ Eating Disorder Not Otherwise Specified. 


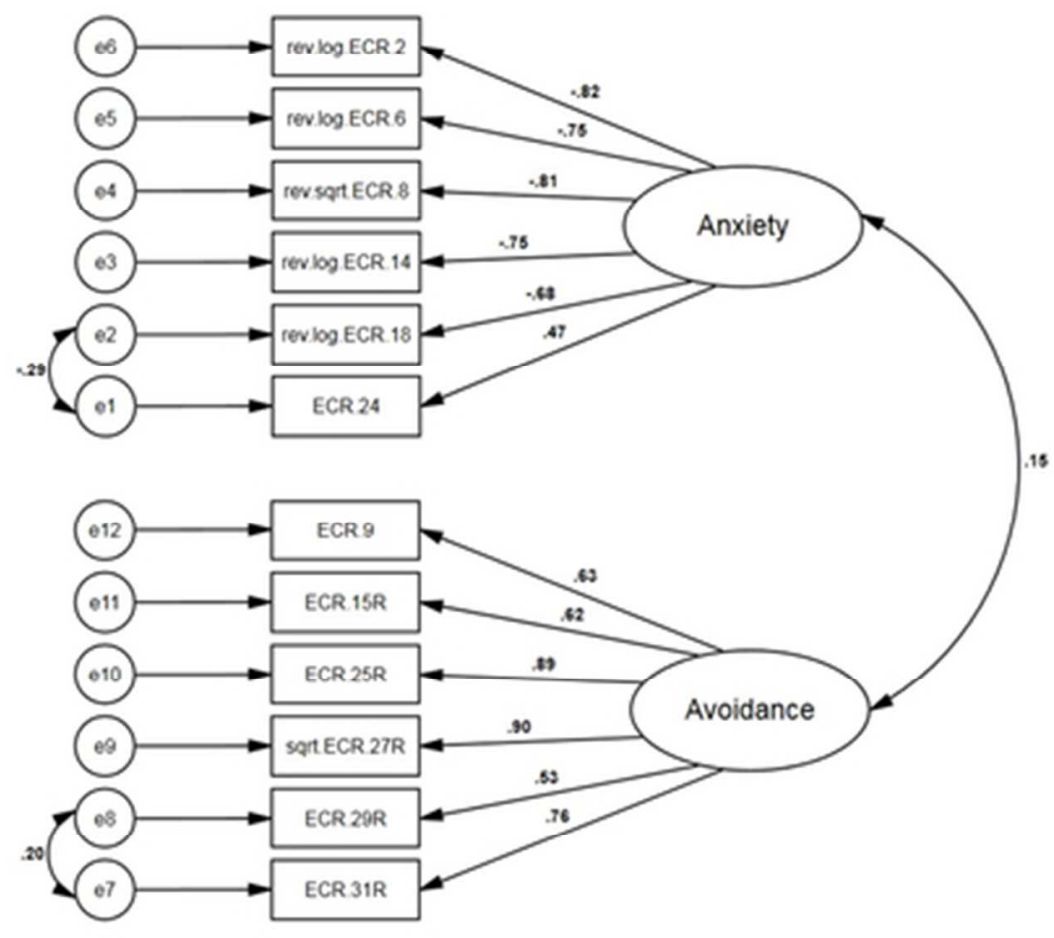

Figure 1. Confirmatory factor analyses on ECR-12 items for the total sample with eating disorders $(\mathrm{N}=$ 1262).

Notes: rev.log = reverse $\log 10$ transformation; rev.sqrt = reverse square-root transformation; sqrt = square-root transformation. Factor loadings between Anxiety and ECR2, 6, 8, 14 and 18, and covariances between e1 and e2 are negative due to fact that variables were reverse transformed. All standardized factor loadings, between-factors and between-error covariances are significant at $p<0.001$.

$$
18 \times 17 \mathrm{~mm}(600 \times 600 \mathrm{DPI})
$$

